\title{
Practical and Theoretical Issues in the Study of Heritage Language Acquisition"
}

\author{
William O'Grady and On-Soon Lee, University of Hawai'i at Manoa \\ Jin-Hwa Lee, Chung-Ang University
}

\begin{abstract}
A promising source of insights into heritage language learning comes from the broader study of the role of input in language acquisition. We concentrate here on the possibility that qualitative differences in the proficiency of heritage and monolingual language learners can be traced to a qualitative difference in the input available to each group. By examining a series of representative phenomena (case, differential object marking, and disjunction), we illustrate how shortfalls in experience can shed light on the many instances of partial acquisition and of attrition that are reported in the literature on heritage language learning.
\end{abstract}

\section{Introduction}

The last several years have seen the growth of interest in the phenomenon of heritage language acquisition, which is characterized by an unusual pattern of exposure to the parental language. In the typical case, heritage learners receive ample exposure to the home language early in life, only to have that exposure end or undergo a dramatic reduction within a matter of years - often at the point where formal schooling begins. It is by now well established that children in this situation manifest linguistic deficiencies in the heritage language in a wide range of areas, including vocabulary (Polinsky \& Kagan, 2007), gender classification (Polinsky,2008a), tense, aspect, and modality (Montrul, 2002; Lynch, 2003; Silva-Corvalán; 2006; Polinsky, 2008b), case paradigms (Polinsky \& Kagan, 2007), the interaction between case and word order (Song, O’Grady, Cho, \& Lee, 1997), relative clauses (O’Grady, Lee \& Choo, 2001; Kim, 2005), agreement (Bolonyai, 2007 for Hungarian), reflexive pronouns (Song, O’Grady, Cho, \& Lee, 1997; Kim \& Montrul, 2004, Kim, Montrul \& Yoon, 2009), differential object marking (Montrul, 2004; Montrul \& Bowles 2009), the semantics of unaccusativity (Montrul, 2005), the contrast between overt and null subjects in 'pro drop' languages (Montrul, 2004), quantifier placement (Polinsky \& Kagan, 2007), and filler-gap dependencies (Polinsky \& Kagan, 2007). Why should this happen?

In this paper, we offer a tentative answer to this question by considering the quality and quantity of the input to which heritage learners have access, suggesting that particular experience-related deficits contribute to partial language acquisition and/or attrition. We begin, in the next section, by considering the importance of input to language acquisition in general. We then turn in section 3 to two case studies that appear to shed light on well-documented deficits in

\footnotetext{
* A version of this paper was presented at the Second Summer Heritage Research Institute, Harvard University, June 23-27, 2008. We thank Olga Kagan, Maria Polinsky, Silvina Montrul, and other audience members for their comments and suggestions.
} 
heritage language acquisition. Section 4 presents an experimental study of a previously unexamined phenomenon in the acquisition of Korean as a heritage language that sheds further light on the role of the input in acquiring and maintaining a heritage language. Section 5 offers some brief concluding remarks.

\section{The Role of Input Strength in Language Acquisition}

It is a matter of consensus that the language acquisition process is dependent upon the availability of appropriate input, in the form of language use by others. Indeed, there are even indications that at least some features of language acquisition are quite directly shaped by the input, consistent with what might be called the Input Strength Hypothesis.

The Input Strength Hypothesis (first version):

The most frequently encountered forms are acquired first and are the most accessible for language use throughout life.

Something like this appears to be true of lexical development, as shown by the fact that toddlers learn frequently presented novel words faster than infrequently presented ones (Schwartz \& Terrell, 1983; Gershkoff-Stowe, 2002) and that even among adults, high-frequency words are retrieved faster and are recognized more quickly than their less frequent counterparts (Jurafsky, 2003). Similar effects have been observed for some syntactic phenomena as well: compared to less frequent sentence types, the ubiquitous subject-verb-object (SVO) pattern of English manifests a faster learning curve in the course of acquisition, is less likely to be lost in the case of aphasia, and is less likely to be derailed in the course of processing (Townsend \& Bever, 2001; Dick, Bates, Wulfeck, Utman, Dronkers, \& Gernsbacher, 2001; Ferreira, 2003).

At least certain inflectional phenomena also show input strength effects. Drawing on detailed longitudinal data from three children, Maratsos (2000) observed that learners come to systematically use irregular past tense forms for frequently heard irregular verbs like go and see before less common verbs such as sink or win. This suggests a frequency effect-irregular past tense forms have to be encountered a certain number of times before they are mastered, and the more frequently occurring forms are acquired first. ${ }^{1}$

In other cases, however, the effect of input on the developmental profile is much harder to discern. For instance, the definite article the is the most frequent word in the English language; yet it comes to be used productively at a relatively late point. Brown (1973, p. 358) reports that use of the articles the and $a$ attains $90 \%$ accuracy considerably later than several less frequent morphemes, including the progressive marker -ing, the plural suffix $-s$, the possessive morpheme - 's, and at least some irregular past tense forms. How can we reconcile such facts with the idea that the input has a major role in shaping the language acquisition process?

\footnotetext{
${ }^{1}$ Maratsos is careful to note (p. 198) that frequency by itself does not account for all variation in the use of overregularized inflection, noting that at least one phonological variable (vowel frequency) is also relevant. See Yang (2002) for an account that involves substantially greater sensitivity to phonological patterning.
} 
We believe that the key to understanding this puzzle lies in the fact that what matters for language acquisition is not so much the frequency of particular forms as it is the frequency of clear-cut instantiations of mappings between form and meaning. That is, children do not learn the past tense suffix or the definite article simply by encountering the forms -ed and the. Rather, learning takes place only to the extent that children encounter situations in which forms can be successfully linked to a corresponding semantic function, thereby creating mappings. We thus revise the Input Strength Hypothesis as follows.

\section{(2) The Input Strength Hypothesis (revised):}

The most frequently instantiated form-meaning mappings are acquired first and are the most accessible for language use throughout life.

In order for an instantiation of a form-meaning mapping in the input to be useful to a learner, two conditions must be met: the form must be audible, and the meaning must be discernable. Crucially, neither condition can be taken for granted, especially in the case of so-called 'grammatical morphemes' (inflection, determiners, auxiliary verbs, etc.).

On the form side, such morphemes are often difficult to identify on the basis of 'bottom-up' (purely acoustic) evidence (e.g., Ellis, 2006, p.171). Herron and Bates (1997) had adult native speakers of English identify semi-homophonous function words and content words (the pronoun $I$ and the noun eye, the auxiliary verb will and the noun will, and so on) that had been spliced into various contexts - some neutral, some appropriate for just the content word, and some appropriate for just the function word. Participants were unable to correctly recognize the word out of its normal context as much as half the time.

On the semantic side, the function of grammatical morphemes is often opaque, even when context is taken into account. Definite articles are a case in point. As Ionin, Zubizaretta and Maldonado (2008) observe, at least two factors are potentially relevant to article systems in languages of the world:

-Definiteness: whether prior discourse, world knowledge, and so on establish the existence and uniqueness of the referent for the hearer as well as the speaker

-Specificity: whether the speaker has in mind a particular referent, which has some property that makes it noteworthy from his/her point of view.

This creates two sorts of problems for language learners. First, the contrast between definiteness on the one hand and specificity on the other is a subtle one, since it presupposes access to the attitude and intention of the speaker and the hearer-something which is often not fully available, of course. And, second, there is a potentially serious confound: definites are often specific, as in the following example from Ionin, Zubizarreta, \& Maldonado (2008).

[+definite, +specific]

I want to talk to the owner of this store - she is my neighbor, and I have an urgent message for her. 
Is the used here because of definiteness - the speaker is referring to someone whose existence is established by general world knowledge (typically a store has a unique owner)? Or is it because of specificity - the speaker intends to refer to a particular person with a noteworthy property (she is a neighbor for whom she has an urgent message)? There is no way to tell, which means there is no unequivocal mapping between the form the and its meaning in this case.

There are some clear-cut cases, of course - as when a learner hears someone say I want to talk to the owner of this store, whoever that is, with a definite but non-specific referent for the noun. But such unambiguous examples of definiteness without specificity may be relatively rare. As Ionin, Zubizaretta, \& Maldonado (2008) observe, 'Given the subtlety of the discourse triggers related to speaker and hearer knowledge, generalizing from them is likely to be a fairly long and difficult process' (pp. 573-74).

In sum, transparent mappings between form and meaning for grammatical morphemes may well be quite sparse, even for frequently occurring forms. In many cases, the mapping will be non-optimal - or will fail altogether, either because the form is imperceptible or because the associated meaning is unclear due to contextual indeterminacy, the presence of confounds, and so forth. When these complications are taken into account and frequency is calculated in terms of successful mappings, we believe that input strength will have a major role to play in understanding the developmental course of language acquisition, including heritage language learning - to which we now turn.

\section{The Effect of Input Deficits on Heritage Learning}

No one knows precisely how much input is required for a language to be acquired and maintained at a satisfactory level of proficiency. However, we do know that children who grow up in a monolingual environment with parents working in a white-collar profession encounter as many of 2.5 million utterances in the course of a typical year (Hart \& Risley, 1995; Pullum \& Scholz, 2002, pp. 44-45). It is highly unlikely that typical heritage learners hear anywhere near that number of utterances in their home language, especially after they begin their schooling.

It seems reasonable to expect that the consequences of this shortfall will be manifested most strongly in form-meaning mappings that are difficult to acquire in the first place. An instructive example in this regard comes from the interaction of case and word order in Korean. In principle, case plays a crucial role in the mapping between form and meaning in that language. Because Korean allows 'free word order,' there are patterns such as (4) in which case is required to indicate which noun refers to the 'actor' and which designates the 'undergoer.'

(4) a. Subject-Direct Object-Verb (SOV) pattern

Yeca-ka namca-lul anacwue.

girl-Nom boy-ACC hug

'The girl is hugging the boy.'

${ }^{2}$ All Korean examples are transliterated using the Yale system of Romanization. 
b. Direct Object-Subject-Verb (OSV) pattern

Namca-lul yeca-ka anacwue.

boy-AcC girl-Nom hug

'The girl is hugging the boy.'

Monolingual Korean children can use case to interpret OSV sentences at above-chance levels by age 4, but heritage learners encounter very significant difficulties well beyond that age. Song, O'Grady, Cho, and Lee (1997) report that the 28 heritage learners in their comprehension study were unable to select the right picture in response to an OSV sentence such as (4b) even at age 8 .
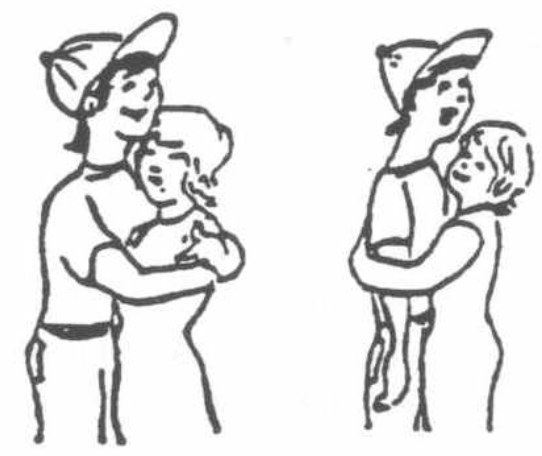

Figure 1 Sample picture used to test for attentiveness to case in the interpretation of the OSV sentence Namca-lul yeca-ka anacwue 'boy-ACC girl-Nom hug'

Why should this be? A plausible hypothesis involves the non-optimal nature of the mapping between form and meaning for Korean case. At least three considerations are relevant.

First, case is frequently dropped in Korean, especially in casual speech. Based on longitudinal data from three mother-child dyads, Cho (1981, pp. 45-46) reports that mothers use the nominative case on subjects slightly more than half the time (56.8\%). The accusative is used for direct objects far less frequently - about $10 \%$ of the time.

Second, the OSV pattern that illustrates the primacy of case over word order in Korean is rarely used. Kwon, Polinsky, and Kluender (2006, p. 3) report that only $1.2 \%$ of the sentences in the Seyjong corpus ${ }^{3}$ manifest this order, and Cho (1981, p. 35) reports comparable figures for maternal speech to children. Moreover, it seems reasonable to suppose that many, perhaps most, of these patterns have an animate subject and an inanimate direct object, making it possible for language learners to infer their meaning without even attending to case marking.

Third, both the nominative and the accusative are associated with more than just the expression of grammatical relations. As Lee (2006, pp. 77-79) reports based on an analysis of the CallFriend Korean corpus of telephone conversations, the accusative is far more commonly used when the direct object is animate and/or definite than when it is inanimate and/or indefinite - an instance of differential object marking (Aissen, 2003). There is a reverse effect for the nominative case, which is more likely to be employed when the subject is inanimate. Matters are

\footnotetext{
${ }^{3}$ The Seyjong corpus consists of approximately 10-million words of spoken and written Korean from a variety of genres.
} 
further complicated by the fact that the nominative case enters into a subtle series of topicalityand focus-related contrasts with the topic marker -(n)un (Choo \& Kwak, 2008, p. 243ff).

In this regard then, Korean children are in a difficult situation. Instead of finding an obligatory one-to-one mapping between a salient form and a single contextually clear semantic factor (the ideal situation implied by Brown 1973, p. 361ff), they encounter a complex statistical association between case and at least three interrelated factors (grammatical relation, animacy, and definiteness). This is clearly an example of a non-optimal mapping between form and meaning.

Acc. Case $<\longrightarrow$ direct object

Optimal mapping

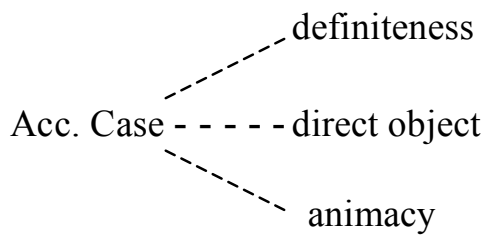

Actual mapping (non-optimal)

Figure 2 Two types of mapping

It seems reasonable to suppose that considerable experience will be required to sort out the effects of the various factors that interact to create the form-meaning mapping associated with Korean case. The accumulation of that experience will almost certainly be made difficult, and perhaps even impossible, by limited or abbreviated exposure to the language.

Now consider differential object marking in Spanish. As Montrul (2004) explains, following Torrego (1998), standard Spanish uses the preposition $a$ when the referent of direct object is both human and specific, but not otherwise. ${ }^{4}(\mathrm{OM}=$ object marker $)$

(5)a. Referent of the direct object is both human and specific

Buscan a un profesor.

search.3PL OM a professor

'They are looking for a particular professor.'

b. Referent of the direct object is human, but not specific (no $a$ )

Buscan un profesor.

search.3PL a professor

'They are looking for any professor.'

c. Referent of the direct object is inanimate (no $a$ )

Buscan un libro.

search.3PL a book

'They are looking for a particular/any book.'

\footnotetext{
${ }^{4}$ Matters are further complicated by the fact that the use of $a$ is sensitive to the animacy of the subject in the case of stative and activity verbs.
} 
As Montrul documents, heritage learners of Spanish have significant difficulty with the use of $a$ to mark objects. Why?

Once again, there is a likely input-related impediment. For one thing, instances of humandenoting direct objects are relatively infrequent in any language - in fact, the whole point about differential object marking is that a special marker (such as $a$ in Spanish) is used for non-typical direct objects. Moreover, not only is the prepositional marker $a$ relatively non-salient (as Montrul observes), but in many contexts it is impossible to know which feature(s) of the direct object call for the preposition - is $a$ used in (6) because the referent of the direct object is human, because it is specific, or both?
Buscan a Juan.
search.3P1 OM Juan
'They are looking for Juan.'

In the face of variables confounded in this way, children simply may not encounter a sufficient number of unambivalent mappings to construct the relevant generalization if the input is interrupted or restricted, as is often the case for heritage language learners.

We suspect that partial acquisition typically has an input-based etiology along the lines illustrated by the examples we have just considered. The acquisition process makes heavy demands on the input in these cases, requiring repeated exposure to clear form-meaning mappings - a salient form linked to a meaning free of confounds and contextual indeterminacy. Yet, as we have seen, many mappings, especially those involving grammatical morphemes, are less than optimal in this regard. Limited and abbreviated input only magnifies the problem, creating the sorts of consequences that we see in heritage language learning.

\section{Attrition-A Case Study}

Input is relevant not only for language acquisition, but also for language maintenance. It is widely recognized that a language that is not used with sufficient frequency in a wide range of situations is subject to attrition (Cook, 2003, p. 12; de Bot, 2004; Goral, Levy, \& Obler, 2002; Jessner, 2003; Köpke, 2007). There are even reports of attrition in adult speakers who acquire their language in a monolingual setting and employ it as a dominant or sole language for many years thereafter (e.g., Dussias, 2004; Tsimpli, Sorace, Heycock, \& Filiaci, 2007).

The fact that attrition can occur even in the case of adult bilinguals not only points to the importance of continued opportunities for language use, but also it raises a difficult research question. To what extent are the deficiencies in heritage learners the result of language attrition rather than partial acquisition?

In principle, the most desirable way to investigate this issue would be to carry out a multiyear longitudinal study (perhaps extending for twenty years or more) involving heritage learners in a variety of settings. In practice, of course, such studies confront many obstacles, and it makes sense to pursue a cross-sectional study in the short term. Here again, a phenomenon in Korean provides an interesting research opportunity. 
It is well known that when the direct object of a negated verb contains or, the connective takes on a conjunctive 'neither nor' interpretation in English (Chierchia, Crain, Guasti, Gualmini, \& Meroni, 2001).

(7) John didn't eat [ice cream or cake].

$=$ 'John ate neither ice cream nor cake.'

(conjunctive interpretation)

In contrast, Japanese manifests a disjunctive 'one or the other' interpretation in this sort of construction (Goro \& Akiba, 2004).

John-wa [aisu ka keeki-o] tabe-nakat-ta.

John-Top ice cream or cake-Acc eat-not-PST

'John didn't eat ice cream OR he didn't eat cake-one or the other.'

(disjunctive interpretation)

Preliminary work by On-Soon Lee (2010) suggests that Korean differs from both English and Japanese in permitting either interpretation, although the 'neither nor' interpretation appears to be dominant.

(9) John-un [aisu khulim ina kheyik-ul] an mek-ess-ta.

John-TOP ice cream or cake-ACC not eat-PST-DECL

'John ate neither ice cream nor cake,' or

'John didn't eat ice cream OR he didn't eat cake - one or the other.'

Because the facts are so subtle and because the relevant sentences (with an or-phrase functioning as direct object of a negated verb) are relatively rare, ${ }^{5}$ this phenomenon is potentially subject to partial acquisition and/or attrition. We therefore conducted an experiment to test for this possibility and to see whether child heritage learners might manifest an understanding of disjunction that has been lost in their adult counterparts.

Participants

There were four groups of participants.

-20 native Korean college students (aged 19-25), who had been raised in Korea in a monolingual setting

-18 native Korean children (aged 3;8 - 5;5), who were being raised in Korea in a monolingual setting

-11 child heritage learners of Korean (aged 3;11 - 8;0), all of whom were living in Honolulu.

-11 adult heritage speakers of Korean, all of whom were living in Honolulu.

\footnotetext{
${ }^{5}$ There are no instances of this pattern in spoken Korean in the Seyjong corpus, and just three examples involving the more formal negative ci anh-ta. It is also worth noting that some Koreans find -ina 'or' unnatural in a negated sentence, regardless of the interpretation it receives. We continue to investigate this matter.
} 
The child heritage learners, all with Korea-born immigrant parents, had acquired Korean as their first language, but had subsequently acquired English as the result of exposure to that language outside the home. All were enrolled in English-language schools. (Additional biographical data can be found in the appendix.) The adult heritage participants were all graduate students in the University of Hawaii's M.A. in Korean for Professions, a program specifically designed for students who had learned Korean as a heritage language but had subsequently become Englishdominant. (Biographical details can be found in the Appendix.) Because they had received at least as much exposure to Korean as children as had our child heritage participants, any sign of a deficit in the adults that is not also present in the children can be plausibly attributed to attrition.

Method and Materials

All participants were tested individually in a quiet place - the children by one native speaker of Korean and the adults by another. The task took children between 20 and 30 minutes to complete; adults typically completed it in 10 minutes or less.

The experiment was administered in two sessions-one to test the 'one or the other' interpretation and one to test the 'neither nor' interpretation. Half the participants within each group took part in the 'one or the other' session first, and the other half took part in the 'neither nor' session first. There was an interval of approximately one week between each session.

Each session began with three 'warm-up' items, followed by 5 test items that were interspersed among 10 filler items, all of which were affirmative or negative sentences without disjunction. The participants' success on the filler items (at least 95\% for all groups) demonstrated that they understood the task and were able to interpret negated sentences in general.

The test materials, which were orally presented entirely in Korean, consisted of a series of illustrated stories that were designed to test for the 'neither nor' versus the 'one or the other' interpretation. The English translation of a sample story follows.

The teacher told a mouse, a pig, and a bear that they should eat all their food for good health. For lunch, there are noodles, cucumber, and French fries. The teacher will give a chocolate to any animal who eats all [the different types of] food. Let's see who got the chocolate. The bear ate only noodles. The mouse ate a cucumber, French fries, and noodles. However, the pig ate only the cucumber and noodles. Who do you think received the chocolate? [Answer: the mouse]

After each story, the participants were asked to evaluate the truth of three sentences (some true and some false) as they looked at an accompanying picture that summarized what had happened in the story.

i. The bear ate noodles. [true]

ii. The pig ate noodles. However, the pig did not eat French fries or cucumber.

[true or false, depending on the interpretation of or]

iii. The mouse did not eat cucumber. [false] 


\section{然}
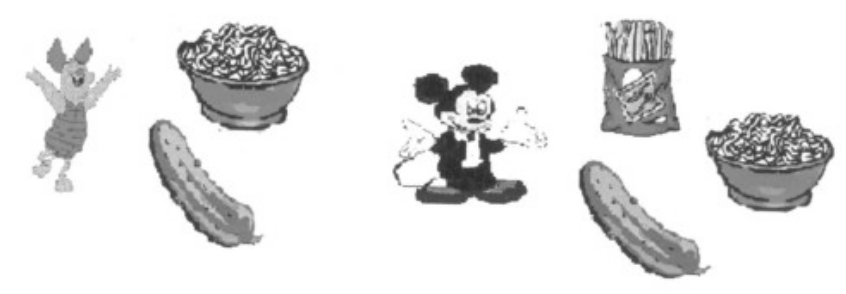

Figure 3 Sample picture from the comprehension experiment

As can be seen by considering the sample story and picture, the second test item is the crucial one, since the answer reveals the interpretation of the or-phrase. A yes response indicates the 'one or the other' interpretation-'The pig either didn't eat French fries or the pig didn't eat cucumber' (the disjunctive interpretation), which is true since the pig did not eat French fries. In contrast, a no response indicates that that participant takes the sentence to mean 'The pig ate neither cucumber nor French fries (the conjunctive interpretation), which is false since the pig ate the cucumber.

Regardless of whether the answer was 'yes' or 'no', the child was asked to give a reason for his/her choice (e.g., 'because the pig ate cucumbers'). The children's rationale for their decisions invariably supported the judgments they had given.

Results

Table 1 summarizes the results for the two groups of participants who were raised in a monolingual setting in Korea.

Table 1. Results from Korean native speakers (adults and children)

\begin{tabular}{lll} 
Participants & $\begin{array}{l}\text { or pattern in } \\
\text { 'neither nor' context } \\
\text { (\% accepted as true) }\end{array}$ & $\begin{array}{l}\text { or pattern in } \\
\text { 'one or the other' context } \\
\text { (\% accepted as true })\end{array}$ \\
\hline adults & $100 \%$ & $33 \%$ \\
children & $100 \%$ & $34 \%$
\end{tabular}

As can be seen here, there was a strong preference for the 'neither nor' interpretation. However, the 'one or the other' interpretation was allowed about a third of the time as well, with nine of the adult participants and twelve of the children accepting it at least once. (Five of the adults and three of the children accepted it on each of the five times they encountered it.) 
Now consider the results for the child heritage learners, summarized in table 2.

Table 2. Results from the child heritage learners

\begin{tabular}{ll}
$\begin{array}{l}\text { or pattern in } \\
\text { 'neither nor' context } \\
(\% \text { accepted as true) }\end{array}$ & $\begin{array}{l}\text { or pattern in } \\
\text { 'one or the other' context } \\
(\% \text { accepted as true })\end{array}$ \\
\hline $90.9 \%$ & $32.7 \%$
\end{tabular}

As can be seen here, the child heritage learners exhibited a preference for the 'neither nor' interpretation. Like the children and adults raised in Korea, they selected that interpretation over $90 \%$ of the time, compared to about one time in three for the 'one or the other' interpretation. (Eight of the 11 child heritage learners chose the 'one or the other' interpretation at least once.) Bearing in mind that all answers had to be justified by an appropriate explanation, it seems clear that the heritage children permit a 'one or the other' interpretation although, like adults, they tend to prefer the 'neither nor' interpretation.

Matters were very different for the adult heritage speakers - they opted for the 'neither nor' interpretation $100 \%$ of the time, invariably rejecting the 'one or the other' interpretation that had been accepted about a third of the time by the adult native speakers, by the child native speakers, and by the child heritage learners.

Table 3. Results from the adult heritage speakers

\begin{tabular}{ll}
$\begin{array}{l}\text {-ina pattern in } \\
\text { 'neither nor' context } \\
(\% \text { accepted as true })\end{array}$ & $\begin{array}{l}\text {-ina pattern in } \\
\text { 'one or the other' context } \\
(\% \text { accepted as true })\end{array}$ \\
\hline $100 \%$ & $0 \%$
\end{tabular}

\section{Discussion}

If these results are representative, then there is reason to think that child heritage learners of Korean manage to acquire the same interpretive preferences for disjunction in negated clauses as monolingual child and native speakers do. As the results reported in Tables 1 and 2 show, all three groups demonstrate a strong preference for the 'neither nor' interpretation, but permit the 'one or the other' reading about a third of the time. The situation is different for adult heritage speakers, however: they show no signs at all of permitting the 'one or the other' interpretation. Given that the background of the adult heritage speakers strongly resembles that of their child counterparts, it seems plausible to assume that they too once allowed the 'one or the other' reading, but that this interpretative option was lost through attrition in the absence of 
opportunities to hear and use structures of this type. This is yet another indication of the importance of input to the outcome of language learning in a heritage setting. ${ }^{6}$

\section{Concluding Remarks}

The view of heritage language learning that we have put forward is essentially an 'activation and strengthening' hypothesis: acquisition takes place as particular form-meaning mappings are activated in response to unambivalent instantiations in the input. Subsequent maintenance of the mapping depends on the extent to which it is strengthened through repeated opportunities for activation, presumably in both production and comprehension. ${ }^{7}$ If this is right, then the first thing to consider as we try to understand the shortfalls associated with heritage language learning is the possibility that certain mappings are difficult to identify and/or sustain in the circumstances in which heritage languages are acquired and used.

As explained in Section 2, language learners can be expected to have trouble with mappings in which either the form has low perceptual salience or the corresponding meaning is clouded by contextual indeterminacy, confounds with other potential contrasts, and so forth. Herein lies the challenge for heritage language learners, whose input is restricted compared to that of children in monolingual environments, precluding the possibility that quantity might somehow compensate for the difficulties presented by non-optimal mappings. Significantly, as the examples considered in Section 3 help illustrate, the sorts of phenomena that have been shown to be problematic for heritage language learners typically make heavy demands on input due to the complex nature of the relevant mappings.

The study of attrition illustrates yet another aspect of the activation and strengthening hypothesis: a mapping that is acquired in childhood may not be maintained if there are few or no opportunities for ongoing use. The interpretation of or in negated sentences is instructive in this regard. As the experimental results reported in section 4 appear to show, the weak 'one or the other' interpretation of this pattern is present in children, including heritage learners, and in adult native speakers, but is unavailable to adult heritage speakers, presumably as a consequence of disuse.

We do not claim that input is the only factor relevant to the deficits typical of heritage language acquisition. Processing considerations are also crucial (O'Grady, Kwak, Lee, and Lee, 2011), as is the possibility of interference from the dominant language (e.g., Ellis, 2006; Yip \& Matthews, 2007). Nonetheless, we propose that the key to understanding the peculiar characteristics of heritage language acquisition - and to finding ways to enhance and maintain heritage languages themselves - lies in the quantitative and qualitative properties of the input to which children are exposed in the early years of life.

\footnotetext{
${ }^{6}$ It may be worth noting in this regard that two of the three children who never accepted the 'one or the other' interpretation were the oldest in our group of child participants.

${ }^{7}$ This idea can be implemented in a variety of frameworks (see, for example, Paradis, 2004; Truscott \& SherwoodSmith, 2004; O'Grady, 2007; Bybee, 2008), and we take no position here on precisely how this should be done.
} 


\section{References}

Aissen, J. (2003). Differential object marking: Iconicity vs. economy. Natural Language and Linguistic Theory, 21, 435-83.

Bolonyai, A. (2007). (In)vulnerable agreement in incomplete bilingual L1 learners. International Journal of Bilingualism, 11, 3-23.

Brown, R. (1973). A First Language: The Early Stages. Cambridge, MA: Harvard University Press.

Bybee, J. (2008). Usage-based grammar and second language acquisition. In P. Robinson \& N. Ellis (Eds.), Handbook of cognitive linguistics and second language acquisition, (pp. 216236). New York: Routledge.

Chierchia, G., Crain, S., Guasti, M. T., Gualmini, A., \& Meroni, L. (2001). The acquisition of disjunction: Evidence for a grammatical view of scalar implicatures. In A. Do, L. Dominguez, \& A. Johansen (eds.), Proceedings of the 25th Boston University Conference on Language Development, pp. 157-68. Somerville, MA: Cascadilla Press.

Cho, S. W. (1981). The acquisition of word order in Korean. Unpublished master's thesis, University of Calgary, Calgary, Alberta, Canada.

Choo, M., \& Kwak, H-Y. (2008). Using Korean. Cambridge, UK: Cambridge University Press.

Cook, V. (2003). Introduction: The changing L1 in the L2 user's mind. In V. Cook (Ed.), Second language acquisition, 3: Effects of the second language on the first (pp. 1-18). Clevedeon, UK: Multilingual Matters.

de Bot, K. (2004). Introduction. International Journal of Bilingualism, 8, 233-237.

Dick, F., Bates, E., Wulfeck, B., Utman, A., Dronkers, N., \& Gernsbacher, M. (2001). Language deficits, localization, and grammar: Evidence for a distributive model of language breakdown in aphasic patients and neurologically intact individuals. Psychological Review, 108, 759788.

Dussias, P. (2004). Parsing a first language like a second: The erosion of L1 parsing strategies in Spanish English bilinguals. International Journal of Bilingualism, 8, 355-71.

Ellis, N. (2006). Selective attention and transfer phenomena in L2 acquisition: Contingency, cue competition, salience, interference, overshadowing, blocking, and perceptual learning. Applied Linguistics, 27, 164-94.

Ferreira, F. (2003). The misinterpretation of noncanonical sentences. Cognitive Psychology, 47, 164-203.

Gershkoff-Stowe, L. (2002). Object naming, vocabulary growth, and the development of word retrieval abilities. Journal of Memory and Language, 46, 665-87.

Goral, M., Levy, E., \& Obler, L. (2002). Neurolinguistic aspects of bilingualism. International Journal of Bilingualism, 6, 411-40.

Goro, T., \& Akiba, S. (2004). The acquisition of disjunction and positive polarity in Japanese. In G. Garding \& M. Tsujimura (Eds.), Proceedings of the 23rd West Coast Conference on Formal Linguistics (pp. 101-14). Somerville, MA: Cascadilla Press.

Hart, B., \& Risley, T. (1995). Meaningful differences in the everyday experience of young American children. Baltimore: Paul H. Brookes.

Herron, D., \&Bates, E. (1997). Sentential and acoustic factors in the recognition of open- and closed-class words. Journal of Memory and Language, 37, 217-39.

Ionin, T., Zubizarreta, M. L., \& Maldonado, S. (2008). Sources of linguistic knowledge in the second language acquisition of English articles. Lingua, 118, 554-76. 
Jessner, U. (2003). A dynamic approach to language attrition in multilingual systems. In V. Cook (Ed.), Second language acquisition, 3: Effects of the second language on the first (pp. 23446). Clevedon, UK: Multilingual Matters.

Jurafsky, D. (2003). Probabilistic modeling in psycholinguistics: Linguistic comprehension and production. In R. Bod, J. Hayy \& S. Jannedy (Eds.), Probabilistic Linguistics (pp. 39-96). Cambridge, MA: MIT Press.

Kim, H-S. (2005). Processing strategies and transfer by heritage and non-heritage learners of Korean. Unpublished Ph.D. dissertation, University of Hawaii at Manoa.

Kim, J-H., \& Montrul, S. (2004). In A. Brugos, L. Micciulla, and C. Smith (eds.), Binding interpretations in Korean heritage speakers. Proceedings of 28th Annual Boston University Conference on Language Development (pp. 307-317). Sommerville, MA: Cascadilla Press.

Kim, J-H., Montrul, S., \& Yoon, J. (2009). Binding interpretations of Korean heritage speakers. Language Acquisition, 16, 3-35.

Köpke, B. (2007). Language attrition at the crossroads of brain, mind, and society. In B. Köpke, M. Schmid, M. Keijzer, S. Dostert . (Eds.), Language attrition: Theoretical perspectives (pp. 9-38). Amsterdam: John Benjamins.

Kwon, N. Polinsky, M., \& Kluender, R. (2006). Subject preference in Korean. In D. Baumer, D. Montero, \& M. Scanlon (Eds.), Proceedings of the 25th West Coast Conference on Formal Linguistics (pp. 1-14). Somerville, MA: Cascadilla.

Lee, H. (2006). Parallel optimization in case systems: Evidence from case ellipsis in Korean. Journal of East Asian Linguistics, 15, 69-96.

Lee, On-Soon. 2010. Acquisition of Korean disjunction under negation. Hawaii Working Papers in Linguistics, 41, 1-12.

Lynch, A. (2003). The relationship between second and heritage language acquisition: Notes on research and theory building. Heritage Language Journal, 1. Retrieved from www.heritagelanguages.org/

Maratsos, M. (2000). More overregularizations after all: New data and discussion on Marcus, Pinker, Ullman, Hollander, Rosen \& Xu. Journal of Child Language, 27, 183-212.

Montrul, S. (2002). Incomplete acquisition and attrition of Spanish tense/aspect distinctions in adult bilinguals. Bilingualism: Language and Cognition, 5, 39-68.

Montrul, S. (2004). Subject and object expression in Spanish heritage speakers: A case of morphosyntactic convergence. Bilingualism: Language and Cognition, 7, 125-42.

Montrul, S. (2005). Second language acquisition and first language loss in adult early bilinguals: Exploring some similarities and differences. Second Language Research, 21, 199-249.

Montrul, S., \& Bolwes, M. (2009). Back to basics: Incomplete knowledge of Differential Object Marking in Spanish heritage speakers. Bilingualism: Language and Cognition 12, 363-83.

O'Grady, W. (2007). The syntax of quantification in SLA: An emergentist approach. In M. O'Brien, C. Shea, \& J. Archibald (Eds.), Proceedings of the 8th Generative Approaches to Second Language Acquisition Conference (GASLA 2006): The Banff Conference (pp. 98113). Somerville, MA: Cascadilla Press.

O'Grady, W., Lee, M., \& Choo, M. (2001). The acquisition of relative clauses by heritage and non-heritage learners of Korean as a second language: A comparative study. Journal of Korean Language Education, 12, 283-94.

O'Grady, W., Kwak, H-Y., Lee, O.-S., \& Lee, M. (2011). An emergentist perspective on heritage language acquisition. Studies in Second Language Acquisition. 33, 223-45.

Paradis, M. (2004). A neurolinguistic theory of bilingualism. Amsterdam: John Benjamins.

Polinsky, M. (2008a). Gender under incomplete acquisition: Heritage speakers' knowledge of noun categorization. Heritage Language Journal, 6(1). Retrieved at http://www.heritagelanguages.org/. 
Polinsky, M. (2008b). Without aspect. In G. Corbett \& M. Noonan (Eds.), Case and grammatical relations (pp. 263-82). Oxford: Oxford University Press.

Polinsky, M., \& Kagan, O. (2007). Heritage languages: In the 'wild' and in the classroom. Language and Linguistics Compass, 1(5), 368-95.

Pullum, G., \& Scholz, B. (2002). Empirical assessment of stimulus poverty arguments. Linguistic Review, 19, 9-50.

Schwartz, R. \& Terrell, B. (1983). The role of input frequency in lexical acquisition. Journal of Child Language, 10, 57-64.

Silva-Corvalán, C. (2006). Aspectos del español en Los Angeles. In A. Ma Cestero, I. Molina, \& F. Paredes (Eds.), Estudios sociolingüísticos del español de España y América (pp. 187194). Madrid: Arco Libros.

Song, M., O'Grady, W., Cho, S., \& Lee, M. (1997). The learning and teaching of Korean in community schools. In Y.-H. Kim (Ed.), Korean language in America, 2 (pp. 111-27). American Association of Teachers of Korean.

Torrego, E. (1998). The dependency of objects. Cambridge, MA: MIT Press.

Townsend, D., \& Bever, T. (2001). Sentence comprehension: The integration of habits and rules. Cambridge, MA: MIT Press.

Truscott, J., \& Sharwood-Smith, M. (2004). Acquisition by processing: A modular perspective on language development. Bilingualism: Language and Cognition, 7, 1-20.

Tsimpli, I., Sorace, A., Heycock, C., \& Filiaci, F. (2007). First language attrition and syntactic subjects: A study of Greek and Italian near-native speakers of English. International Journal of Bilingualism, 8, 257-77.

Yang, C. (2002). Knowledge and learning in natural language. New York: Oxford University Press.

Yip, V., \& Matthews, S. (2007). The bilingual child: Early development and language contact. Cambridge, UK: Cambridge University Press. 


\section{Appendix}

Biographical Information for Adult Heritage Speakers

\begin{tabular}{rrrrrrrr}
\hline $\begin{array}{r}\text { Student } \\
\text { ID }\end{array}$ & Age & Gender & $\begin{array}{r}\text { Birth } \\
\text { place }\end{array}$ & $\begin{array}{r}\text { Age } \\
\text { of } \\
\text { arrival }\end{array}$ & $\begin{array}{r}\text { Age of } \\
\text { Exposure } \\
\text { to Korean }\end{array}$ & $\begin{array}{r}\text { Age of } \\
\text { Exposure } \\
\text { to English }\end{array}$ & $\begin{array}{r}\text { Parents' } \\
\text { Language }\end{array}$ \\
\hline 1 & 30 & f & Korea & $9: 0$ & birth & $9: 11$ & Korean \\
2 & 23 & f & Korea & $4: 0$ & birth & $4: 10$ & Korean \\
3 & 24 & m & Korea & $9: 0$ & birth & 6 & Korean \\
4 & 33 & f & Korea & $1: 3$ & birth & $1: 03$ & Korean \\
5 & 26 & f & Korea & $12: 0$ & birth & 11 & Korean \\
6 & 31 & f & Korea & $3: 0$ & birth & 5 & Korean \\
7 & 24 & f & USA & n/a & birth & birth & Korean \\
8 & 25 & f & USA & n/a & birth & 4 & Korean \\
9 & 22 & f & USA & n/a & birth & 3 & Korean \\
10 & 24 & f & USA & n/a & birth & 4 & Korean \\
11 & 23 & f & USA & n/a & birth & birth & Korean
\end{tabular}

Biographical Information for Child Heritage Learners

\begin{tabular}{|c|c|c|c|c|c|c|c|}
\hline $\begin{array}{r}\text { Student } \\
\text { ID }\end{array}$ & Age & Gender & $\begin{array}{l}\text { Birth } \\
\text { place }\end{array}$ & $\begin{array}{r}\text { Age } \\
\text { of } \\
\text { arrival } \\
\end{array}$ & $\begin{array}{r}\text { Age of } \\
\text { Exposure } \\
\text { to } \\
\text { Korean }\end{array}$ & $\begin{array}{r}\text { Age of } \\
\text { Exposure } \\
\text { to } \\
\text { English }\end{array}$ & $\begin{array}{r}\text { Parents' } \\
\text { Language }\end{array}$ \\
\hline 1 & $6 ; 6$ & $\mathrm{~F}$ & USA & $\mathrm{n} / \mathrm{a}$ & birth & 4 & Korean \\
\hline 2 & $6 ; 4$ & M & USA & $\mathrm{n} / \mathrm{a}$ & birth & $2 ; 6$ & Korean \\
\hline 3 & $8 ; 0$ & M & USA & $\mathrm{n} / \mathrm{a}$ & birth & $5 ; 0$ & Korean \\
\hline 4 & $6 ; 6$ & $\mathrm{~F}$ & Korea & $2 ; 6$ & birth & $3 ; 7$ & Korean \\
\hline 5 & $8 ; 0$ & $\mathrm{~F}$ & USA & $\mathrm{n} / \mathrm{a}$ & birth & $4 ; 0$ & Korean \\
\hline 6 & $5 ; 0$ & $\mathrm{M}$ & USA & $\mathrm{n} / \mathrm{a}$ & birth & $3 ; 0$ & Korean \\
\hline 7 & $3 ; 11$ & $\mathrm{~F}$ & USA & $\mathrm{n} / \mathrm{a}$ & birth & birth & Korean \\
\hline 8 & $8 ; 0$ & M & USA & $\mathrm{n} / \mathrm{a}$ & birth & birth & Korean \\
\hline 9 & $6 ; 10$ & $\mathrm{~F}$ & USA & $\mathrm{n} / \mathrm{a}$ & birth & $2 ; 8$ & Korean \\
\hline 10 & $5 ; 10$ & $\mathrm{~F}$ & USA & $\mathrm{n} / \mathrm{a}$ & birth & $3 ; 1$ & Korean \\
\hline 11 & $3 ; 11$ & $\mathrm{~F}$ & USA & $\mathrm{n} / \mathrm{a}$ & birth & $2 ; 0$ & Korean \\
\hline average & $5 ; 5$ & $7(\mathrm{f}) / 4(\mathrm{~m})$ & & & & $2 ; 5$ & \\
\hline
\end{tabular}

